autoantibody profile including myositis specific autoantibodies (MSAs) and myositis associated autoantibodies (MAAs).

Results: Compared to HCs, patients with IIMs more frequently had prolongation of QTc ( $p=0.037)$ and QRS ( $p=0.031)$. All patient groups had significantly longer QTC and QRS duration than HCs. In multivariate regression analysis of patients with IIMs, increased CRP ( $p=0.006)$ was associated to increased QTc. Pooled data for patients with IIMs and HCs showed an association between diagnosis of IIM and increased QTc duration $(p<0.001)$. An association between presence of any MAA and QRS duration appeared in patients with IIMs $(p=0.019)$. In pooled data for patients with IIMs and HCs, diagnosis of IIM was associated with QRS duration $(p=0.001)$

Table: Multivariate regression analyses of explanatory factors for QTc duration (ms)

\begin{tabular}{|c|c|c|c|c|c|c|c|c|}
\hline \multirow{2}{*}{$\begin{array}{l}\text { Risk factor } \\
\text { Gender, male }\end{array}$} & \multirow{2}{*}{$\begin{array}{l}\text { OR } \\
0.46 \\
\end{array}$} & \multicolumn{2}{|c|}{$95 \% \mathrm{Cl}$} & \multirow{2}{*}{$\begin{array}{c}\begin{array}{c}P- \\
\text { value }\end{array} \\
0.002\end{array}$} & \multirow{2}{*}{$\begin{array}{c}\text { OR } \\
0.46\end{array}$} & \multicolumn{2}{|c|}{$95 \% \mathrm{Cl}$} & \multirow{2}{*}{$\begin{array}{r}\text { P-value } \\
0.001\end{array}$} \\
\hline & & 0.28 & 0.75 & & & 0.29 & 0.72 & \\
\hline Age at inclusion, per year & 1.02 & 0.99 & 1.04 & 0.068 & 1.02 & 1.00 & 1.04 & 0.047 \\
\hline Hypertension, no vs. yes & 1.63 & 0.93 & 2.86 & 0.086 & 1.58 & 0.97 & 2.60 & 0.069 \\
\hline $\begin{array}{l}\text { Former/present smoker, no } \\
\text { vs. yes }\end{array}$ & 1.35 & 0.84 & 2.17 & 0.213 & 1.57 & 1.02 & 2.41 & 0.041 \\
\hline $\begin{array}{l}\text { Increased CRP, no vs. yes } \\
\mathrm{BMI}, \mathrm{kg} / \mathrm{m}^{2}\end{array}$ & 2.17 & 1.25 & 3.75 & $\begin{array}{c}0.006 \\
\text { NS }\end{array}$ & 1.98 & 1.15 & 3.40 & $\begin{array}{l}0.013 \\
\text { NS }\end{array}$ \\
\hline $\begin{array}{l}\text { Dyspnea (NYHAll-IV), no vs. } \\
\text { yes }\end{array}$ & & & & NS & & & & NS \\
\hline $\begin{array}{l}\text { Presence of MSAs/MAAs, no } \\
\text { vs. yes }\end{array}$ & & & & NS & NA & NA & NA & NA \\
\hline $\begin{array}{l}\text { HAQ (Health Assessment } \\
\text { Questionnaire), 0-3 }\end{array}$ & & & & NS & NA & NA & NA & NA \\
\hline IIM, no vs. yes & NA & NA & NA & NA & 4.11 & 2.21 & 7.63 & $<0.001$ \\
\hline
\end{tabular}

Conclusions: Patients with IIMs, no matter of clinical subgroup, had a higher occurrence of cardiac abnormalities detected by ECG than HCs. Increased CRP and presence of any MAA were associated with increased QTc and QRS duration, respectively. These results support our notion of possible associations between inflammation and autoimmunity and cardiac affection in patients with IIMs. There is now a pressing need to set up a larger prospective study to validate the present findings.

Disclosure of Interest: None declared

DOI: 10.1136/annrheumdis-2018-eular.6830

\section{SAT0499 ASSOCIATION BETWEEN SYSTEMIC SCLEROSIS AND OTHER SYSTEMIC AUTO-IMMUNE DISEASES: STUDY IN TWO UNIVERSITY HOSPITALS COHORTS}

M. Scherlinger ${ }^{1}$, J. Lutz $^{2}$, J. Sibilia² ${ }^{2}$ E. Chatelus ${ }^{2}$, M.-E. Truchetet ${ }^{1}$.

${ }^{1}$ Rheumatology, CHU de Bordeaux, Bordeaux; ${ }^{2}$ Rheumatology, CHU de

Strasbourg, Strasbourg, France

Background: Association between systemic sclerosis (SSc) and another autoimmune systemic disease (AISD) in the same patient seems to be more frequent than each disease's prevalence would explain.

Objectives: The aim of our work was to describe patients presenting an overlap syndrome from 2 french cohorts and to compare their characteristics with patients presenting SSc alone.

Methods: This was a retrospective observational study conducted in two french auto-immune diseases reference centre (Strasbourg and Bordeaux). Patients responding to the 2013 ACR-EULAR scleroderma classification criteria for SSc were screened for concomitant AISD. Patients satisfying 2010 ACR-EULAR diagnostic criteria for rheumatoid arthritis (RA) and/or 2016 ACR-EULAR classification criteria for Gougerot-Sjögren syndrome (GSS) and/or 2012 SLICC systemic lupus erythematosus (SLE) classification criteria were included in our study. Patient, disease, and treatment characteristics were retrospectively retrieved from medical records and were compared to a SSc control cohort for Bordeaux University Hospital.

Results: A population of 534 SSc patients was studied. Thirty-four (6.4\%) patients were identified as having overlap syndrome. There was $21(62 \%$, prevalence $3.9 \%$ ) patients with RA, 14 (41\%, prevalence $2.6 \%)$ with GSS and $4(12 \%$, prevalence $0.7 \%$ ) with SLE (5 patients had 2 AISD).

There were $24(71 \%)$ patients with limited cutaneous SSc. Median Rodnan was 6 (extreme 0-42), 13 (38\%) patients had interstitial pneumonia and 9 (26\%) presented lung fibrosis. Three patients had pulmonary arterial hypertension (PAH) confirmed with catheterism. Seventeen patients $(50 \%)$ had anti-centromere $\mathrm{Ab}$, $11(32 \%)$ had anti-Scl70 Ab whereas none had anti-RNA-polymerase III Ab (investigated in 24 patients).

Concerning RA patients, 17 (81\%) were ACPA-positive and 17 (81\%) had erosive disease. Only 6 (29\%) were in remission according to Boolean criteria and 13 $(62 \%)$ had a DAS28-CRP $\leq 3.2$ suggesting difficult-to-treat RA. Patients with GSS all presented sicca syndrome, $8(57 \%)$ had a Chisholm grade $\geq 3$ on accessory salivary gland biopsy and $12(86 \%)$ had positive anti-SSA Ab. In patients with SLE, $3(75 \%)$ had positive anti-DNA Ab and one had a grade IV kidney disease Three $(75 \%)$ patients with SLE had a SLICC organ-damage score $\geq 5$ suggesting severe SLE.

Compared with our control cohort, patients with overlap syndrome had higher frequency of corticosteroid, immunosuppresive and biologic therapy use (85.3\% vs $45 \% ; 70.6 \%$ vs $31.3 \% ; 52.9$ vs $3.8 \% ; p<0.0001$ for all comparisons).

Conclusions: Association of SSc and another auto-immune systemic disease is present in more than $6 \%$ of patients. These patients might have a more severe disease than usual SSc patients requiring prompt diagnosis and adequate treatment. Disclosure of Interest: None declared

DOI: 10.1136/annrheumdis-2018-eular.2227

\section{SAT0500 MYOCARDIAL INVOLVEMENT AT MAGNETIC RESONANCE IN PATIENTS WITH SYSTEMIC SCLEROSIS AND MINOR ARRHYTHMIAS: ASSOCIATION WITH CLINICAL FEATURES AND IMPACT OF TREATMENT}

M. De Santis ${ }^{1}$, L. Monti ${ }^{2}$, M. Briani ${ }^{3}$, E. Indolfi ${ }^{3}$, E. Generali ${ }^{1}$, N. Isailovic ${ }^{1}$, A. Ceribelli ${ }^{1}$, G.M. Guidelli ${ }^{1}$, M. Caprioli ${ }^{1}$, M. Meroni ${ }^{1}$, C. Selmi ${ }^{1,4}{ }^{1}$ Rheumatology and Clinical Immunology; ${ }^{2}$ Radiology; ${ }^{3}$ Cardiology, Humanitas Research Hospital, Rozzano; ${ }^{4}$ Biometra Department, University of Milan, Milan, Italy

Background: Systemic sclerosis (SSc) is an autoimmune fibrotic disease characterised by variable clinical manifestations based on the predominant organ involvement. With the exceptions of acute fulminant myocarditis with pericardia effusion and heart failure, myocardial involvement in SSc is clinically silent until arrhythmias appear, while representing the major cause of sudden death or atrioventricular (AV) blocks in SSc. There are no reliable screening algorithm to dis criminate myocardial involvement nor established treatments.

Objectives: To identify early/clinically silent myocardial involvement in SSc and define a possible treatment.

Methods: We used Holter electrocardiography (ECG) to investigate our cohort of patients with $S S c$ ( $n=221$, all fulfilling the ACR classification criteria) for ventricular ectopic beats (VEB)/AV blocks/unexplained tachycardia as sensitive signs of myocardial involvement. In 24 patients (women 23\%-95.8\%, anti-centromereACA 16\%-66.6\%, anti-topoisomerase-aScl70 3\%-12.5\%, anti-RNA polimerase III 3\%-12.5\%, anti-Ku $2 \%-8.3 \%$, limited skin disease-ISSc $12 \%-50 \%$, diffuse skin disease $5 \%-20.8 \%$, sine scleroderma $7 \%-29.2 \%$, median age 66.5 years, IQR 57.8-72.5), never treated with anti-fibrotic agents, we performed heart mag netic resonance (hMR) searching for myocardial oedema (on T2 STIR sequences, using the signal ratio between myocardium and skeletal muscle with a cut-off value of $\geq 1.9$ for oedema) or fibrosis (presence of any late gadolinium enhancement (LGE) with intramyocardial or subepicardial pattern). Patients with myocardial oedema at hMR were treated with mycophenolate mofetil (MFM) $2 \mathrm{~g} / \mathrm{day}$ or with azathioprine (AZA) $100 \mathrm{mg} /$ day and underwent a control hMR after six months.

Results: In 10/24 (42\%) of the SSc cases with Holter ECG alterations (8 VEB, 1 tachycardia, 1 type II AV block) we observed SSc myocardial involvement at hMR. In more detail, 6 patients had myocardial oedema at T2 STIR sequences (including cases as follows: 1 aScl70-positive with ISSc and lung fibrosis, 2 ACApositive with ISSc, 3 ACA-positive sine scleroderma), and 4 only fibrosis (1 Scl70 positive with ISSc and lung fibrosis, 1 ACA-positive with ISSc, 1 ACA-positive sine scleroderma, 1 anti-Ku-positive sine scleroderma). At 6 months of medical treat ment, myocardial oedema disappeared in 3 patients treated with Aza and in treated with MFM, the additional 2 patients are still receiving MFM treatment at the time of analysis.

Conclusions: We observed that $42 \%$ of patients with SSc and minor arrhythmias on 24 hour Holter ECG have clinically silent myocardial involvement at hMR those with potential reversible disease (oedema rather than fibrosis) favourably respond to immunosuppressants. Detectable serum ACA and the absence of skin involvement are over-represented in this subgroup of patients.

Disclosure of Interest: None declared

DOI: 10.1136/annrheumdis-2018-eular 6859

\section{SAT0501 EARLY VERSUS LATE-ONSET SYSTEMIC SCLEROSIS: ARE THERE CLINICAL AND IMMUNOLOGICAL DIFFERENCES?}

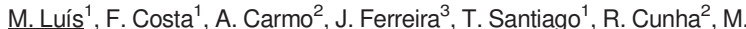
J. Salvador ${ }^{1}$, J. da Silva ${ }^{1} .{ }^{1}$ Rheumatology, ${ }^{2}$ Clinical Pathology, ${ }^{3}$ Cardiology, Centro Hospitalar e Universitário de Coimbra, Coimbra, Portugal

Background: The clinical course of Systemic Sclerosis (SSc) depends on subtype, organ involvement and age. Peak age at onset of SSc is between 30 and 50 
years, although SSc may also start in both young and elderly patients. Few data have been reported on patients suffering from late-onset SSc.

Objectives: To characterise clinical and immunological features of early and lateonset SSc in a tertiary referral hospital.

Methods: We analysed data from 178 patients followed at our SSc clinic. All the patients fulfilled the ACR/EULAR 2013 classification criteria for SSc or the LeRoy's criteria for the classification of early SSc.

Based on the mean of age of onset of the whole series ( $50 \pm 15$ years), ages extremes were defined as younger than 35 versus older than 65 years of age at onset. Disease characteristics as well as clinical and immunological features were evaluated.

Results: The early and the late-onset groups included 35 and 31 patients, respectively. Patients' current mean age was $42.8 \pm 14.1$ vs. $75.8 \pm 6.2$ with a mean disease duration of $14.5 \pm 14.7$ vs. $4.3 \pm 4$.6 years. The most common first manifestation of disease was Raynaud phenomena followed by arthritis/inflammatory arthralgia, in both groups. However, the time between clinical onset and SSc diagnosis was higher in the late-onset group $(p=0.034)$. A higher number of diffuse and pre-SS was observed in the early group but this difference didn't prove statistically significant. There was a higher prevalence of centromere antibodies in the late-onset group $(p=0.001)$. Clinical manifestations and target-organ damage didn't differ between groups, except for a higher prevalence of heart conduction abnormalities in the late-onset group ( $\mathrm{p}=0.02)$. In multivariate analyses, age alone $(\mathrm{OR}=1.04 ; 95 \% \mathrm{Cl} 1.0,1.1)$, but not disease duration (OR=0.99; 95\% $\mathrm{Cl} 0.9-1.0)$, was an independent predictor for the presence of heart conduction abnormalities.

Abstract SAT0501 - Table 1. Demographic, clinical and immunological features of Early and Late-Onset SSc Patients. Abbreviations: $y r=$ years; $S S c=$ Systemic Sclerosis. * confirmed by esophageal manometry. ${ }^{* *}$ Based on pulmonary function tests with diffusing capacity of lung for carbon monoxide. ${ }^{* * *}$ Diagnosed with echocardiography and confirmed by right heart catheterization wherever available.

\begin{tabular}{|c|c|c|c|}
\hline & $\begin{array}{l}\text { Early-Onset Group } \\
(\text { (s } 35 \mathrm{yr}), \mathrm{n}=35\end{array}$ & $\begin{array}{l}\text { Late-Onset Group } \\
(\geq 65 \mathrm{yr}), \mathrm{n}=31\end{array}$ & p \\
\hline Sex (male:female) & $6: 29$ & 5:26 & 0.912 \\
\hline Age at diagnosis (yr) & $28.3 \pm 5.4$ & $71.4 \pm 4.7$ & $<0.001$ \\
\hline Time until diagnosis (yr) & 4.3 & 8.5 & 0.034 \\
\hline $\begin{array}{l}\text { First manifestation (\%) } \\
\text { - Raynaud } \\
\text { - Arthritis/Arthralgia }\end{array}$ & $\begin{array}{l}82.9 \\
14.3\end{array}$ & $\begin{array}{l}62.1 \\
20.7\end{array}$ & $\begin{array}{l}0.061 \\
0.499\end{array}$ \\
\hline $\begin{array}{l}\text { Type of SSc (\%) } \\
\text { - Pré-SSc } \\
\text { - Limited } \\
\text { - Diffuse }\end{array}$ & $\begin{array}{l}37.1 \\
34.3 \\
22.9\end{array}$ & $\begin{array}{l}25.8 \\
41.9 \\
12.9\end{array}$ & $\begin{array}{l}0.324 \\
0.523 \\
0.295\end{array}$ \\
\hline $\begin{array}{l}\text { Capillaroscopy pattern (\%) } \\
\text { - SSc specific } \\
\text { - Unspecific } \\
\text { - Normal }\end{array}$ & $\begin{array}{l}51.7 \\
31.0 \\
17.2\end{array}$ & $\begin{array}{r}52.9 \\
41.2 \\
5.9\end{array}$ & $\begin{array}{l}0.936 \\
0.486 \\
0.270\end{array}$ \\
\hline Raynaud phenomena (\%) & 100 & 92.9 & 0.113 \\
\hline Digital ulcers (\%) & 48.5 & 30.8 & 0.169 \\
\hline Arthritis/arthralgia (\%) & 63.6 & 44.4 & 0.137 \\
\hline Esophageal involvement (\%)" & 31.2 & 33.3 & 0.865 \\
\hline Interstitial lung disease (\%)"* & 28.1 & 26.9 & 0.919 \\
\hline Pulmonary arterial hypertension $(\%) \cdots$ & 12.5 & 29.6 & 0.103 \\
\hline Heart conduction alteration (\%) & 18.8 & 48.1 & 0.016 \\
\hline Anticentromere antibodies (\%) & 45.7 & 87.1 & $<0.001$ \\
\hline Anti-Scl 70 antibodies (\%) & 17.1 & 3.2 & 0.067 \\
\hline Anti-nuclear antibodies (\%) & 94.3 & 100 & 0.401 \\
\hline
\end{tabular}

Conclusions: In line with findings from other studies, late-onset SSc shows a distinct clinical and immunological presentation. The present study confirms that late-onset is associated with longer diagnostic delay, positive centromere and heart conduction abnormalities. These observations may be due to age and potential age-associated confounders, rather than the disease itself. Knowledge of these different characteristics can help to improve the management of the disease.

\section{REFERENCES:}

[1] Alba M, et al. Early-versus Late-Onset Systemic Sclerosis. Medicine 2014;93(2):73-81.

[2] Hugle T, et al. Late-onset systemic sclerosis - a systemic survey of the EULAR scleroderma trials and research group database. Rheumatology (Oxford) 2010;50(1):161-5.

[3] Manno R, et al. Late-Age Onset Scleroderma. J. Rheumatol 2011;38 (7):1317-1325.

Disclosure of Interest: None declared

DOI: 10.1136/annrheumdis-2018-eular.3984

\section{SAT0502 COMPARISON OF THE CREATININE-BASED AND THE CYSTATIN C-BASED ESTIMATED GLOMERULAR FUNCTION (EGFR) IN PATIENTS WITH SYSTEMIC SCLEROSIS PATIENTS}

M. Krusche, T. Kubacki, R. Osei-Davies, I. Kötter. Rheumatologie, klinische Immunologie und Nephrologie, AK Altona, Hamburg, Germany

Background: Kidney involvement is common in systemic sclerosis (SSc) and proteinuria or renal crisis are associated risk factors for increased mortality in SSc.

For the measurement of the kidney function (glomerular filtration rate, GFR) the creatinine-based estimation formula of the Chronic Kidney Disease Epidemiology Collaboration (CKD-EPI) and the Modification of Diet in Renal Diseases (MDRD)formula are commonly used.

Cystatine $\mathrm{C}$ has a higher diagnostic sensitivity to show a reduction of GFR. As it is not being influenced by muscle mass or diet it has an advantages over the creatinine-based measurements.

Objectives: Comparison of the creatinine-based and cystatin C-based eGFR in systemic sclerosis patients.

Methods: Single-centre, retrospective analysis of SSc patients between 20152017 which were parallel tested for serum creatinine and cystatine $C$.

108 patients (78 females, 30 males), 21 patients with diffuse systemic sclerosis (dcSSc), 76 patients with limited systemic sclerosis (IcSSc) and 11 patients with overlap syndrome. Medium age 58,8 ( $\pm 16,1$ years), age span 17-83 years.

For the calculation of the estimated glomerular filtration rate (eGFR) the following formulas were used: MDRD-Study Equation, CKD-EPI Creatinine Equation 2009 CKD-EPI Cystatin C Equation 2012

Results: The mean eGFR according to the CKD-EPI Creatinine Equation was $84,4 \mathrm{ml} / \mathrm{min}( \pm 23,5)$, according to the MDRD formula it was $80,24 \mathrm{ml} / \mathrm{min}( \pm 22,8)$ $(p<0,001)$ and $65,3 \mathrm{ml} / \mathrm{min}( \pm 21,7)(p<0,001)$ when the CKD-EPI Cystatin C Equation was used. According to the KDIGO stages of chronic renal impairment a stage G2 (eGFR $<90 \mathrm{ml} / \mathrm{min}$ ) was present in $39,8 \%$ of the patients $(43 / 108)$ using the CKD-EPI Creatinine Equation, in 47,2\% (51/108) using MDRD and in 48,1\% (52/ 108) using the CKD-EPI Cystatin C Equation.

A relevant chronic kidney impairment stage G3 (eGFR $<60 \mathrm{ml} / \mathrm{min}$ ) or higher was present in $14,8 \%$ of the patients (16/108) calculated by CKD-EPI Creatinine Equation, in $17,6 \%(19 / 108)$ of the patients according to MDRD Equation and in $38,8 \%$ (42/108) according to CKD-EPI Cystatin C Equation.

Patients with a higher difference (>18 $\mathrm{ml} / \mathrm{min}$ ) between creatinine-based and cystatin C-based eGFR did not differ in age, body mass index (BMI) or disease subset from patients with a lower difference but a higher difference occurred significantly more often in men $(p=0,012)$.

Conclusions: Many patients with SSc showed a significant difference using cystatin $\mathrm{C}$ for the calculation of GFR compared to the creatinine-based formulas. As reduced muscle mass is common in SSc this could be due to sarcopenia in the context of the underlying disease. Early detection of impaired kidney function might be useful to monitor disease progress and is important for the management of immunosuppressive drugs like methotrexate and cyclophosphamide which are commonly used in the disease but need to be adjusted to the renal function.

A prospective study with measurement of GFR and comparison of different formulas in this patient population seems necessary.

Disclosure of Interest: None declared

DOI: 10.1136/annrheumdis-2018-eular.4675

\section{SAT0503 ASSESSMENT OF PROSTANOIDS (ILOPROST, ALPROSTADIL) EFFICACY IN TREATMENT OF ULCERS IN PATIENTS WITH SYSTEMIC SCLEROSIS}

M. Starovoytova, O. Desinova, O. Koneva, O. Ovsyannikova, L. Garzanova. VA Nasonova Research Institute of Rheumatology, Moscow, Russian Federation

Background: The prostanoids are currently regarded as the most effective agents in treatment of ischaemic lesions in patients with rheumatic diseases. However, the efficacy of Alprostadil is underexplored, especially in comparison with lloprost.

Objectives: To evaluate the efficacy of Alprostadil (Vazaprostan ${ }^{\circledR}$ ) and Iloprost $\left(\right.$ Ilomedin $\left.{ }^{\circledR}\right)$ in treatment of digital ulcers in SSc pts using modern assessment tools (questionnaires and designated forms) of digital ulcers.

Methods: This 1 year study included 42 patients with systemic scleroderma (SSc) aged $>18 \mathrm{y}$, having digital ulcers. Standard evaluation procedures and questionnaire to assess therapy, as well as scales and questionnaires for assessment of digital ulcers were used at baseline and after 12 months. The therapeutic regimens were as follows: Alprostadil at $20 \mathrm{mg} / \mathrm{kg}$ i/v drip rate infusion during 10 days, 1 course in 6 mo (totally 2 courses). lloprost at $20 \mathrm{mg} / \mathrm{kg} \mathrm{i} / \mathrm{v}$ via infusion pump during 5 days each 3 months (totally 2 courses).

The following questionnaires/forms to evaluate the therapy of digital ulcers were used: 1/VAS for pain assessment, 2/SSc-HAQ, 3/Cochin hand function scale, 4/ the total hand pain score, 5/global patient's assessment of ulcers, 6/global 